\title{
REVIEW
}

\section{Use of Ceftaroline Fosamil in Children: Review of Current Knowledge and its Application}

\author{
Juwon Yim (D) - Leah M. Molloy · Jason G. Newland
}

Received: November 10, 2016 / Published online: December 30, 2016

(C) The Author(s) 2016. This article is published with open access at Springerlink.com

\begin{abstract}
Ceftaroline is a novel cephalosporin recently approved in children for treatment of acute bacterial skin and soft tissue infections and community-acquired bacterial pneumonia (CABP) caused by methicillin-resistant Staphylococcus aureus, Streptococcus pneumoniae and other susceptible bacteria. With a favorable tolerability profile and efficacy proven in pediatric patients and excellent in vitro activity against resistant Gram-positive and Gram-negative bacteria, ceftaroline may serve as a therapeutic option for polymicrobial
\end{abstract}

Enhanced content To view enhanced content for this article go to http://www.medengine.com/Redeem/ 1F47F0601BB3F2DD.

J. Yim $(\bowtie)$

St. John Hospital and Medical Center, Detroit, MI, USA

e-mail: ft0702@wayne.edu

L. M. Molloy

Children's Hospital of Michigan, Detroit, MI, USA

J. G. Newland

St. Louis Children's Hospital, St. Louis, MO, USA

J. G. Newland

Washington University School of Medicine,

St. Louis, MO, USA infections, CABP caused by penicillin- and ceftriaxone-resistant $S$. pneumoniae and resistant Gram-positive infections that fail first-line antimicrobial agents. However, limited data are available on tolerability in neonates and infants younger than 2 months of age, and on pharmacokinetic characteristics in children with chronic medical conditions and those with invasive, complicated infections. In this review, the microbiological profile of ceftaroline, its mechanism of action, and pharmacokinetic profile will be presented. Additionally, clinical evidence for use in pediatric patients and proposed place in therapy is discussed.

Keywords: Antibiotic resistance; Ceftaroline fosamil; Children; Methicillin-resistant Staphylococcus aureus; Streptococcus pneumoniae

\section{INTRODUCTION}

Antibiotic resistance in Gram-positive bacteria is steadily increasing, posing a growing health concern worldwide [1, 2]. Likewise, antibiotic treatment failures have been reported among 
children with invasive infections caused by resistant Gram-positive bacteria [3, 4]. Management of these infections in pediatric patients may be even more challenging due to limited therapeutic options. Antibiotics approved by the US Food and Drug Administration (FDA) for treatment of infections caused by methicillin-resistant Staphylococcus aureus (MRSA) in children are limited to vancomycin, clindamycin and linezolid [5]. Daptomycin has been increasingly used in pediatrics despite the lack of safety and efficacy data [6]. Finally, for newer antibiotics such as telavancin, dalbavancin and oritavancin, the lack of pharmacokinetic and clinical studies severely restricts their use in pediatric infections [7].

Ceftaroline is a new cephalosporin with an FDA-approved indications for acute bacterial skin and skin structure infections (ABSSI) caused by MRSA and community-acquired bacterial pneumonia (CABP) caused by Streptococcus pneumoniae and other susceptible bacteria in children 2 months of age and older [8]. In this review, the microbiological profile of ceftaroline, its mechanism of action, and pharmacokinetic characteristics will be presented. Additionally, clinical evidence for use in pediatric patients will be discussed.

\section{Compliance with Ethics Guidelines}

The analysis in this article is based on previously conducted studies, and does not involve any new studies of human or animal subjects performed by any of the authors.

\section{Antimicrobial Activity and Pharmacology of Ceftaroline}

Ceftaroline is known as a novel "fifth-generation cephalosporin" that exhibits in vitro bactericidal activity against MRSA $[9,10]$. It is also active against other bacteria common in childhood infections, such as $S$. pneumoniae, S. pyogenes, Haemophilus influenzae and Moraxella catarrhalis [11].

Ceftaroline, like other $\beta$-lactams, exerts bactericidal effects by binding to penicillin-binding proteins (PBPs) to inhibit cell wall synthesis [12]. Ceftaroline is distinguished from other $\beta$-lactams by its enhanced affinity for mutated PBPs that render other $\beta$-lactams ineffective against $S$. aureus and S. pneumoniae [13]. In S. aureus, the mecA gene-encoded mutant PBP2a confers methicillin resistance while $\beta$-lactam resistance in $S$. pneumoniae results from modification in PBP1A, PBP2X, and PBP2B [14, 15]. Unlike other $\beta$-lactams, ceftaroline has unique greater affinity for these altered PBPs by which it retains activity against MRSA and penicillin-resistant S. pneumoniae. Additionally, ceftaroline has activity against commonly encountered Gram-negative bacteria in children including $H$. influenzae, Klebsiella species and Escherichia coli. However, it does not have activity against Gram-negative bacteria producing extended-spectrum $\beta$-lactamase (ESBL) or carbapenemase [16].

In international surveillance studies with clinical isolates, ceftaroline $\mathrm{MIC}_{90}$ for MSSA and MRSA were $0.25-0.5 \mathrm{mg} / \mathrm{L}$ and $1-2 \mathrm{mg} / \mathrm{L}$, respectively. Even though ceftaroline MICs for MRSA isolates were four-fold higher than MSSA isolates, a majority of $S$. aureus isolates were susceptible to ceftaroline. Of note, ceftaroline retained activity against heterogeneous vancomycin-intermediate $S$. aureus, with MICs ranging from 0.25 to $4 \mathrm{mg} / \mathrm{L} \quad[16,17]$. Ceftaroline additionally exhibits excellent activity against $S$. pneumoniae isolates regardless of its susceptibility to other antimicrobials, with $\mathrm{MIC}_{90}$ of $\leq 0.016$ and 
$0.25 \mathrm{mg} / \mathrm{L}$ for penicillin-susceptible and penicillin-resistant $S$. pneumoniae isolates, respectively [16]. Furthermore, it demonstrates significant activity against cephalosporin-resistant $S$. pneumoniae strains, supporting its role in treatment of multi-drug resistant $S$. pneumoniae infections [18].

Another potentially important pharmacological characteristic is the low propensity of Gram-positive pathogens to develop resistance to ceftaroline. Mutant selection did not occur in Gram-positive bacteria evaluated in vitro, including $S$. aureus and $S$. pneumoniae after repeated exposure to ceftaroline [19, 20]. However, clinical implication of the in vitro finding is not yet fully understood, and the emergence of resistance to ceftaroline during a course of therapy has been reported, even though extremely rare $[21,22]$. Currently, prevalence of ceftaroline-resistant organisms appears to be fairly rare in surveillance studies conducted in the United States, with 97.6\% MRSA strains and $100 \%$ S. pneumoniae strains being susceptible to ceftaroline [23, 24].

\section{Pharmacokinetics}

Basic pharmacokinetic parameters known to date are based on adult studies. Ceftaroline is administered as a water-soluble prodrug, ceftaroline fosamil, which is rapidly metabolized by a phosphatase enzyme to bioactive ceftaroline and later hydrolyzed to microbiologically inactive metabolite ceftaroline M-1 [25]. It yields dose-proportional increases in maximum plasma concentration $\left(C_{\max }\right)$ and area under the curve (AUC) after administration of single doses of 50-1000 mg. Repeated administration of ceftaroline for 14 days appears to result in no appreciable accumulation of the drug. Average protein binding of ceftaroline is low, estimated at $\sim 20 \%$ [8]. Ceftaroline is not substrate, inducer or inhibitor of any major CYP isoenzymes, minimizing potential for drug-drug interactions [26]. Ceftaroline and its metabolites are eliminated mainly by the kidneys, necessitating dose adjustment for renally impaired patients with creatinine clearances of $\leq 50 \mathrm{~mL} / \mathrm{min}[8,27]$.

The pharmacodynamic (PD) parameter most predictive of efficacy is the percentage of the dosing interval during which serum-free ceftaroline concentration remains above the MIC (\% $f \mathrm{~T}>\mathrm{MIC})$. In a study using murine thigh and lung infection models, the average $\% f \mathrm{~T}>\mathrm{MIC}$ needed for bacteriostasis was $26 \pm 8 \%$ for $S$. aureus and $39 \pm 9 \%$ for $S$. pneumoniae [28]. A Monte Carlo simulation of ceftaroline $600 \mathrm{mg}$ every $12 \mathrm{~h}$ given to healthy adults predicted $f \mathrm{~T}>\mathrm{MIC}$ of $71 \%$ and $51 \%$ for organisms with MICs of 1 and $2 \mathrm{mg} / \mathrm{L}$, respectively. Probability of target attainment of $40 \% \mathrm{fT}>\mathrm{MIC}$ was $100 \%$ at an MIC of $1 \mathrm{mg} / \mathrm{L}$ and $90 \%$ at an MIC of $2 \mathrm{mg} / \mathrm{L}[29,30]$.

In pediatric patients, approved ceftaroline dosing regimens are $8 \mathrm{mg} / \mathrm{kg}$ every $8 \mathrm{~h}$ in children from 2 months to $<2$ years of age. In children and adolescents aged 2 years and older, ceftaroline $12 \mathrm{mg} / \mathrm{kg}$ every $8 \mathrm{~h}$ is recommended for patients weighing $\leq 33 \mathrm{~kg}$, and $400 \mathrm{mg}$ every $8 \mathrm{~h}$ or $600 \mathrm{mg}$ every $12 \mathrm{~h}$ for those weighing $>33 \mathrm{~kg}$. In population PK modeling and simulations by Riccobene et al. [31], these regimens were predicted to produce ceftaroline exposure in children similar to that in adults treated with ceftaroline $600 \mathrm{mg}$ every $12 \mathrm{~h}$. The modeled dose regimens attained 36\% $f \mathrm{~T}>\mathrm{MIC}$ (median \% $\mathrm{T} \mathrm{T}>\mathrm{MIC}$ associated with 1-log kill of S. aureus) at a MIC of $2 \mathrm{mg} / \mathrm{L}$ in $>90 \%$ of children and $44 \% \quad f \mathrm{~T}>\mathrm{MIC}$ (median $\% f \mathrm{~T}>\mathrm{MIC}$ associated with 1-log kill of $S$. pneumoniae) at MIC of $1 \mathrm{mg} / \mathrm{L}$ in $97 \%$ of 
children [31]. With $\mathrm{MIC}_{90}$ of $1 \mathrm{mg} / \mathrm{L}$ and $0.12 \mathrm{mg} / \mathrm{L}$ for MRSA and $S$. pneumoniae in the US, respectively [17, 24], currently approved dosing regimens are predicted to maintain adequate PD target in a majority of pediatric patients. Of interest, ceftaroline $6 \mathrm{mg} / \mathrm{kg}$ every $8 \mathrm{~h}$ was expected to produce adequate ceftaroline exposure and successful PD target attainment in neonates and infants younger than 2 months of age, which is being evaluated in this specific pediatric population with late-onset sepsis (NCT02424734) [31, 32].

However, special consideration should be given to children with medical conditions that may alter the pharmacokinetics of ceftaroline, such as cystic fibrosis (CF). In these patients, the $\beta$-lactams have an increased total body clearance and larger volume of distribution due to malnutrition and reduced adipose tissue resulting in lower drug serum concentrations [33]. In a report of a 6-year-old CF patient with MRSA (ceftaroline MIC $=1 \mathrm{mg}$ / L) who was given a dose of $\sim 11 \mathrm{mg} / \mathrm{kg}$ every $8 \mathrm{~h}$, the $C_{\max }$ was $8.99 \mathrm{mg} / \mathrm{L}$ and $\% f \mathrm{~T}>\mathrm{MIC}$ was only $21 \%$ [34]. In contrast, non-CF children of the same age group receiving the approved dose of $12 \mathrm{mg} / \mathrm{kg}$ every $8 \mathrm{~h}$ had a $C_{\max }$ of $27.6 \mathrm{mg} / \mathrm{L}$ (90\% prediction interval of $16.4-43.3 \mathrm{mg} / \mathrm{L}$ ) and 85.2\% $f \mathrm{~T}>\mathrm{MIC}(90 \%$ prediction interval of $61.7-100 \%$ T > MIC) [31, 34]. Even though the patient clinically improved [34], the suboptimal exposure in children with CF could lead to emergence of ceftaroline resistance with repeated exposure as reported by Cannavino et al. [21]. Currently, very little data exist to guide optimal ceftaroline dosing in children with chronic medical conditions and complicated disease states including CNS infections and osteomyelitis. Pharmacokinetic studies targeting children with these conditions are on-going in the hope for further guidance in the future [35-37].

\section{Clinical Efficacy and Safety}

\section{FDA-Labeled Indications}

In May 2016, the FDA approved ceftaroline for the treatment of ABSSI and CABP among children as young as 2 months of age [8]. This approval was based on two randomized, controlled observer-blinded studies primarily evaluating safety in children [38, 39]. Study doses were essentially the same as what is currently approved (Table 1), with the exception of increasing the dose from $8 \mathrm{mg} / \mathrm{kg}$ to $12 \mathrm{mg} / \mathrm{kg}$ every $8 \mathrm{~h}$ for children 6 months- 2 years of age. Additionally, the study allowed for a maximum dose of $400 \mathrm{mg}$ every $8 \mathrm{~h}$, but did not offer the alternative option of $600 \mathrm{mg}$ every $12 \mathrm{~h}$ as appears in the package insert.

The CABP study compared ceftaroline to ceftriaxone $75 \mathrm{mg} / \mathrm{kg} /$ day (maximum daily dose of $4 \mathrm{~g}$ ) and excluded patients with suspected MRSA or Pseudomonas spp., or requiring intensive care unit (ICU) admission. Patients in both groups were treated for a mean total of 10 days including initial intravenous (IV) antibiotics for a minimum of 3 days plus transition to oral therapy, which was typically amoxicillin/clavulanate [38]. Within the modified intent-to-treat (mITT) population (i.e. received at least one dose of study drug), clinical cure rates were comparable with $88 \%$ $(n=94 / 107)$ success in the ceftaroline group and $89 \%(n=32 / 36)$ in the comparator group at the test of cure (TOC) visit conducted between 8 and 15 days after cessation of therapy. In a meta-analysis of 3 clinical trials evaluating ceftaroline in adults hospitalized with severe CABP (Pneumonia Outcomes Research Team risk class 3-4), however, ceftaroline $600 \mathrm{mg}$ every $12 \mathrm{~h}$ was demonstrated to be superior to ceftriaxone $1-2 \mathrm{~g}$ every $24 \mathrm{~h}$ as empiric treatment. Of note, the therapeutic benefit of 
Table 1 Approved and suggested ceftaroline dosing strategies

\begin{tabular}{lll}
\hline & $\begin{array}{l}\text { FDA approved } \\
\text { CABP and ABSSSI }\end{array}$ & $\begin{array}{l}\text { Suggested }^{\text {a }} \\
\text { CCABP, CF, MRSA bacteremia/endocarditis }\end{array}$ \\
\hline 2 months to & $24 \mathrm{mg} / \mathrm{kg} /$ day divided every $8 \mathrm{~h}$ & Age $<6$ months: $30 \mathrm{mg} / \mathrm{kg} /$ day divided every $8 \mathrm{~h}$ \\
$<2$ years & & Age 6 months to $<2$ years: $45 \mathrm{mg} / \mathrm{kg} /$ day divided every \\
& & $8 \mathrm{~h}$ \\
2 to $<18$ years & $36 \mathrm{mg} / \mathrm{kg} /$ day divided every $8 \mathrm{~h}$ & $45 \mathrm{mg} / \mathrm{kg} /$ day divided every $8 \mathrm{~h}$ \\
& Maximum $1200 \mathrm{mg} /$ day, divided every & Maximum $1800 \mathrm{mg} /$ day, divided every $8 \mathrm{~h}$ \\
& $8-12 \mathrm{~h}$ & \\
\hline
\end{tabular}

FDA Food and Drug Administration, CABP community-acquired bacterial pneumonia, MRSA methicillin-resistant Staphylococcus aureus, ABSSSI acute bacterial skin and skin structure infection, $c C A B P$ complicated community-acquired bacterial pneumonia, $C F$ cystic fibrosis

${ }^{a}$ Limited data, not prospectively evaluated for safety outside of cCABP

ceftaroline was not observed in a subgroup of patients with prior antibiotic use within $96 \mathrm{~h}$ [40].

The ABSSI study used the same dosing scheme as the CABP trial and randomized patients to receive ceftaroline or a comparator regimen (vancomycin or cefazolin, with or without aztreonam) [39]. Patients with serious infections involving bones and joints, burns, bite wounds and necrotizing infections were excluded, as were those with pathogens not susceptible to the study drugs. The median total duration of therapy in each group was approximately 10 days including initial IV treatment plus oral cephalexin, clindamycin or linezolid. Again, in the mITT population at the TOC visit, the clinical cure rates were similar, $94 \%(n=101 / 107)$ in the ceftaroline group versus $87 \% \quad(n=45 / 52)$ in the comparator group [39].

In both studies, incidences of treatment-emergent adverse events were comparable between ceftaroline and comparators ( $45 \%$ vs. $46 \%$ in the CABP study; $22 \%$ vs. $23 \%$ in the ABSSI study). However, in the CABP study, seroconversion to a positive Direct Coombs' test, a known effect of ceftaroline, was observed in 17\% $(n=19 / 112)$ of patients in the ceftaroline group and 3\% (1/ 37 ) of patients in the ceftriaxone group. Conversion rates were similar in the ABSSI study $(17 / 99,17 \%$ in the ceftaroline group and $2 / 48,4 \%$ in the comparator group) and no events of hemolysis or hemolytic anemia occurred in any of the patients who experienced seroconversion [38, 39].

\section{Off-Label Use}

An additional pediatric clinical study compared ceftaroline monotherapy to ceftriaxone plus vancomycin for the treatment of complicated CABP (CCABP) [41]. Included patients met the same criteria previously used for enrollment in the CABP study, plus one of several indicators of complicated disease including empyema, ICU admission or pleural effusion requiring chest tube, plus acute symptom onset or worsening. Ceftaroline dosing in this study differed from past studies and what is available in the current package insert; patients under 6 months of age received $10 \mathrm{mg} / \mathrm{kg} /$ dose every $8 \mathrm{~h}$, and patients aged 6 months or older received $15 \mathrm{mg} / \mathrm{kg} /$ dose every $8 \mathrm{~h}$ up to a maximum dose of $600 \mathrm{mg}$ every $8 \mathrm{~h}$. Among the mITT population, clinical 
cure at the TOC visit was $90 \%(n=26 / 29)$ for patients who received ceftaroline and 100\% $(n=9 / 9)$ for those who received ceftriaxone plus vancomycin. Treatment-emergent adverse events occurred in $40 \%(n=12 / 30)$ of the ceftaroline group and $80 \%(n=8 / 10)$ of the vancomycin plus ceftriaxone group. The study drug was discontinued secondary to adverse events (increased liver enzymes and rash with pruritis) in 2 patients, both in the ceftaroline group. Similar to the other studies, 26\% $(n=6$ / 23) of patients who received ceftaroline had Direct Coombs test seroconversion, none of whom experienced hemolysis or hemolytic anemia [41].

The most common reported adverse drug reactions for ceftaroline are rash, fever and gastrointestinal effects [8]. Additionally, transient blood dyscrasias have been described in recent case reports including agranulocytosis in both an adolescent and an adult [42, 43], and a probable interaction between ceftaroline and warfarin yielding a significantly supratherapeutic INR in an adult patient [44]. A $10-20 \%$ incidence of neutropenia with prolonged use has also been reported in retrospective reviews of adult patients $[45,46]$.

As reviewed above, the ceftaroline doses studied and ultimately approved for use in children were derived from a PK model that targeted exposures in children similar to those in adults receiving $600 \mathrm{mg}$ every $12 \mathrm{~h}$ [31]. However, higher doses up to $600 \mathrm{mg}$ every $8 \mathrm{~h}$ for adults and $10-15 \mathrm{mg} / \mathrm{kg} /$ dose every $8 \mathrm{~h}$ in children have been described in case reports of successful salvage treatment of invasive MRSA infections including bacteremia and endocarditis, and also cystic fibrosis exacerbations [34, 47-51]. Similarly, in case reports describing use of ceftaroline for treatment of bacterial meningitis (4S. pneumoniae and $1 S$. aureus) in 5 adults, 4 patients who received ceftaroline $600 \mathrm{mg}$ every $8 \mathrm{~h}$ were successfully treated while 1 patient receiving ceftaroline $600 \mathrm{mg}$ every $12 \mathrm{~h}$ failed the treatment, suggesting that higher doses than currently approved may also be necessary for successful treatment of meningitis in children [52]. While the higher doses of $10-15 \mathrm{mg} / \mathrm{kg} / \mathrm{dose}$ every $8 \mathrm{~h}$ were studied prospectively in the pediatric cCABP trial, the median duration of ceftaroline in that study was 9 days [41]. Salvage treatment of complicated endovascular infections is anticipated to be significantly longer, and retrospective data indicate a higher incidence of neutropenia among patients receiving ceftaroline for prolonged duration. Thus, should prolonged ceftaroline treatment be considered for salvage treatment of an invasive infection, vigilant monitoring for safety is warranted throughout the entire treatment course.

\section{Role in Therapy}

While vancomycin currently remains the preferred treatment for children with invasive MRSA infections, its use is limited by PK variability, toxicities and reported treatment failure rates of between 30\% and 50\% among children with MRSA bacteremia [53, 54]. As such, pediatricians are often forced to consider alternative treatments for serious infections such as linezolid or daptomycin, each of which has unique limitations. As a bacteriostatic agent, linezolid is not preferred for endovascular infections, and daptomycin is not currently approved for use in children for any indication $[55,56]$. Therefore, ceftaroline may be an attractive option given its bactericidal effects and FDA approval for use in children, but caution must be exercised as it is not approved for invasive MRSA infections, safety and efficacy data describing use outside of 
approved indications remain extremely limited, and alternative dosing and monitoring strategies are likely warranted.

Ceftaroline provides potent activity against both MRSA and susceptible Enterobacteriaceae in the absence of ESBL production, AmpC induction or other resistance mechanisms. While most data reviewed here describe the beneficial role of ceftaroline in drug-resistant or refractory Gram-positive infections, good antimicrobial stewardship practice entails selection of narrower spectrum antibiotics targeted only toward confirmed and suspected pathogens. Like other oxyimino cephalosporins such as ceftazidime and ceftriaxone, ceftaroline is a weak inducer of AmpC $\beta$-lactamase [57]. Comparably, exposure to ceftazidime or ceftriaxone has been identified as an independent risk factor for infection with cephalosporin-resistant Enterobacter spp., a pathogen well known to develop $\beta$-lactam resistance per AmpC $\beta$-lactamase [58, 59], and the same risks may be reasonably expected with ceftaroline [57]. As such, ceftaroline may be best positioned for the ideal, albeit uncommon, scenario of concomitant infection with both MRSA and Enterobacteriaceae [60], while use in isolated Gram-positive infections should potentially be reserved for intolerance or failure of narrower spectrum antibiotics targeted only against Gram-positive organisms and for CABP by penicillin- or ceftriaxone-resistant $S$. pneumoniae strains.

\section{CONCLUSION}

Ceftaroline is a new cephalosporin with activity against bacteria commonly encountered in pediatric infections including MRSA, penicillin-resistant and other cephalosporin-resistant S. pneumoniae isolates,
H. Influenzae as well as non-ESBL-producing Enterobacteriaceae spp. It is approved for management of ABSSI caused by MRSA and CABP caused by $S$. pneumoniae and other susceptible bacteria in children over 2 months of age. With potent activity against a wide spectrum of bacteria and efficacy and safety established in children, ceftaroline may serve as a valuable antibiotic in cases of antibiotic intolerance or failure of first-line antibiotics in Gram-positive, CABP caused by suspected or proven penicillin- or ceftriaxone resistant $S$. pneumoniae strains, and polymicrobial infections with MRSA and some Gram-negative bacteria.

Despite these therapeutic benefits in children, limited information is available evaluating its use in management of more serious infections that may warrant more aggressive therapy. In addition, pharmacokinetic data in neonates and infants younger than 2 months of age are lacking. Clinical trials are on-going to address the clinical question of how to optimally treat children with CF, CNS infections and osteomyelitis. Like other antibiotics, the excess and inappropriate use will likely lead to antibiotic resistance. Additionally, ceftaroline like other oxyimino cephalosporins will likely induce the production of AmpC $\beta$-lactamase among Enterobacter species [57]. Thus, ceftaroline will need to be monitored by institutional antimicrobial stewardship programs to assure its use is reserved for appropriate clinical situations.

\section{ACKNOWLEDGEMENTS}

No funding or sponsorship was received for this study or publication of this article. All named authors meet the ICMJE criteria for authorship 
for this manuscript, take responsibility for the integrity of the work as a whole, and have given final approval for the version to be published.

Disclosures. Juwon Yim and Leah M. Molloy declare that they have no conflicts of interest. Jason G. Newland has a grant pending from Merck regarding the evaluation of antimicrobial stewardship programs.

Compliance with Ethics Guidelines. The analysis in this article is based on previously conducted studies, and does not involve any new studies of human or animal subjects performed by any of the authors.

Open Access. This article is distributed under the terms of the Creative Commons Attribution-NonCommercial 4.0 International License (http://creativecommons.org/licenses/ by-nc/4.0/), which permits any noncommercial use, distribution, and reproduction in any medium, provided you give appropriate credit to the original author(s) and the source, provide a link to the Creative Commons license, and indicate if changes were made.

\section{REFERENCES}

1. Boucher HW, Talbot GH, Bradley JS, et al. Bad bugs, no drugs: no ESKAPE! An update from the Infectious Diseases Society of America. Clin Infect Dis. 2009;48(1):1-12.

2. Larru B, Gong W, Vendetti N, et al. Bloodstream infections in hospitalized children: epidemiology and antimicrobial susceptibilities. Pediatr Infect Dis J. 2016;35(5):507-10.

3. Dowell SF, Smith T, Leversedge K, Snitzer J. Failure of treatment of pneumonia associated with highly resistant pneumococci in a child. Clin Infect Dis. 1999;29(2):462-3.

4. Jacobson LM, Milstone AM, Zenilman J, Carroll KC, Arav-Boger R. Daptomycin therapy failure in an adolescent with methicillin-resistant Staphylococcus aureus bacteremia. Pediatr Infect Dis J. 2009;28(5):445-7.

5. Syriopoulou V, Dailiana Z, Dmitriy N, Utili R, Pathan R, Hamed K. Clinical experience with daptomycin for the treatment of Gram-positive infections in children and adolescents. Pediatr Infect Dis J. 2016;35(5):511-6.

6. Larru B, Cowden CL, Zaoutis TE, Gerber JS. Daptomycin use in United States children's hospitals. J Pediatric Infect Dis Soc. 2015;4(1):60-2.

7. Bradley JS, Puttagunta S, Rubino CM, Blumer JL, Dunne M, Sullivan JE. Pharmacokinetics, safety and tolerability of single dose dalbavancin in children $12-17$ years of age. Pediatr Infect Dis J. 2015;34(7):748-52.

8. Allergan. Prescribing information: TEFLARO ${ }^{\circledR}$ (ceftaroline fosamil) for injection. 2016.

9. Kollef MH. New antimicrobial agents for methicillin-resistant Staphylococcus aureus. Crit Care Resusc. 2009;11(4):282-6.

10. Laudano JB. Ceftaroline fosamil: a new broad-spectrum cephalosporin. J Antimicrob Chemother. 2011;66(Suppl 3):iii11-8.

11. Morrissey I, Ge Y, Janes R. Activity of the new cephalosporin ceftaroline against bacteraemia isolates from patients with community-acquired pneumonia. Int $\mathrm{J}$ Antimicrob Agents. 2009;33(6):515-9.

12. Ishikawa $\mathrm{T}$, Matsunaga $\mathrm{N}$, Tawada $\mathrm{H}$, et al. TAK-599, a novel $N$-phosphono type prodrug of anti-MRSA cephalosporin T-91825: synthesis, physicochemical and pharmacological properties. Bioorg Med Chem. 2003;11(11):2427-37.

13. Kosowska-Shick K, McGhee PL, Appelbaum PC. Affinity of ceftaroline and other beta-lactams for penicillin-binding proteins from Staphylococcus aureus and Streptococcus pneumoniae. Antimicrob Agents Chemother. 2010;54(5):1670-7.

14. Kosowska K, Jacobs MR, Bajaksouzian S, Koeth L, Appelbaum PC. Alterations of penicillin-binding proteins 1A, 2X, and 2B in Streptococcus pneumoniae isolates for which amoxicillin MICs are higher than penicillin MICs. Antimicrob Agents Chemother. 2004;48(10):4020-2.

15. Nagai K, Davies TA, Jacobs MR, Appelbaum PC. Effects of amino acid alterations in penicillin-binding proteins (PBPs) $1 \mathrm{a}, 2 \mathrm{~b}$, and $2 \mathrm{x}$ on PBP affinities of penicillin, ampicillin, amoxicillin, cefditoren, cefuroxime, cefprozil, and cefaclor in 18 clinical isolates of 
penicillin-susceptible, -intermediate, and -resistant pneumococci. Antimicrob Agents Chemother. 2002;46(5):1273-80.

16. Sader HS, Fritsche TR, Kaniga K, Ge Y, Jones RN. Antimicrobial activity and spectrum of PPI-0903M (T-91825), a novel cephalosporin, tested against a worldwide collection of clinical strains. Antimicrob Agents Chemother. 2005;49(8):3501-12.

17. Jones RN, Mendes RE, Sader HS. Ceftaroline activity against pathogens associated with complicated skin and skin structure infections: results from an international surveillance study. J Antimicrob Chemother. 2010;65(Suppl 4):iv17-31.

18. McGee L, Biek D, Ge Y, et al. In vitro evaluation of the antimicrobial activity of ceftaroline against cephalosporin-resistant isolates of Streptococcus pneumoniae. Antimicrob Agents Chemother. 2009;53(2):552-6.

19. Clark C, McGhee P, Appelbaum PC, Kosowska-Shick K. Multistep resistance development studies of ceftaroline in gram-positive and -negative bacteria. Antimicrob Agents Chemother. 2011;55(5):2344-51.

20. Mushtaq S, Warner M, Ge Y, Kaniga K, Livermore DM. In vitro activity of ceftaroline (PPI-0903M, T-91825) against bacteria with defined resistance mechanisms and phenotypes. J Antimicrob Chemother. 2007;60(2):300-11.

21. Cannavino CR, Mendes RE, Sader HS, et al. Evolution of ceftaroline-resistant MRSA in a child with cystic fibrosis following repeated antibiotic exposure. Pediatr Infect Dis J. 2016;35(7):813-5.

22. Sanchez EH, Mendes RE, Sader HS, Allison GM. In vivo emergence of ceftaroline resistance during therapy for MRSA vertebral osteomyelitis. J Antimicrob Chemother. 2016;71(6):1736-8.

23. Flamm RK, Sader HS, Farrell DJ, Jones RN. Antimicrobial activity of ceftaroline tested against drug-resistant subsets of Streptococcus pneumoniae from US medical centers. Antimicrob Agents Chemother. 2014;58(4):2468-71.

24. Sader HS, Flamm RK, Streit JM, Farrell DJ, Jones RN. Ceftaroline activity against bacterial pathogens frequently isolated in US medical centers: results from five years of the AWARE surveillance program. Antimicrob Agents Chemother. 2015;59(4):2458-61.

25. Biek D, Critchley IA, Riccobene TA, Thye DA. Ceftaroline fosamil: a novel broad-spectrum cephalosporin with expanded anti-Gram-positive activity. J Antimicrob Chemother. 2010;65(Suppl 4):iv9-16.
26. Riccobene TA, Rekeda L, Rank D, Llorens L. Evaluation of the effect of a supratherapeutic dose of intravenous ceftaroline fosamil on the corrected QT interval. Antimicrob Agents Chemother. 2013;57(4):1777-83.

27. (FDA) TFaDA. Ceftaroline fosamil for the treatment of community-acquired bacterial pneumonia and complicated skin and skin structure infections FDA briefing document for Anti-Infective Drugs Advisory Committee Meeting. 2010 September 7.

28. Andes D, Craig WA. Pharmacodynamics of a new cephalosporin, PPI-0903 (TAK-599), active against methicillin-resistant Staphylococcus aureus in murine thigh and lung infection models: identification of an in vivo pharmacokinetic-pharmacodynamic target. Antimicrob Agents Chemother. 2006;50(4):1376-83.

29. Ge Y, Liao S, Thye DA, Talbot GH. Ceftaroline (CPT) dose adjustment recommendations for subjects with mild or moderate renal impairment (RI). Abstracts of the Forty-seventh Interscience Conference on Antimicrobial Agents and Chemotherapy, Chicago, IL, 2007 Sep 17.

30. Ge Y, Liao S, Talbot GH. Population pharmacokinetics (PK) analysis of ceftaroline (CPT) in volunteers and patients with complicated skin and skin structure infection (cSSSI). Abstracts of the Forty-seventh Interscience Conference on Antimicrobial Agents and Chemotherapy; 2007; Chicago, IL. Washington, DC: American Society for Microbiology; Abstract A-34.

31. Riccobene TA, Khariton T, Knebel W, et al. Population PK modeling and target attainment simulations to support dosing of ceftaroline fosamil in pediatric patients with acute bacterial skin and skin structure infections and community-acquired bacterial pneumonia. J Clin Pharmacol. 2016. doi:10.1002/jcph.809.

32. ClinicalTrials.gov. Safety, tolerability and efficacy of ceftaroline in paediatrics with late-onset sepsis. ClinicalTrials.gov identifier: NCT02424734. [updated September 2016; cited 2016 October 2]. https://clinicaltrials.gov/ct2/show/NCT02424734.

33. Touw DJ, Vinks AA, Mouton JW, Horrevorts AM. Pharmacokinetic optimisation of antibacterial treatment in patients with cystic fibrosis. Current practice and suggestions for future directions. Clin Pharmacokinet. 1998;35(6):437-59.

34. Molloy L, Snyder AH, Srivastava R, Rybak MJ, McGrath E. Ceftaroline fosamil for methicillin-resistant Staphylococcus aureus pulmonary exacerbation in a pediatric cystic 
fibrosis patient. J Pediatr Pharmacol Ther. 2014;19(2):135-40.

35. ClinicalTrials.gov. Ceftaroline for treatment of hematogenously acquired Staphylococcus aureus osteomyelitis in children: ClinicalTrials.gov Identifier NCT02335905 [cited 2016 October 2]. https://clinicaltrials.gov/ct2/show/NCT02335905? term=ceftaroline\&rank $=21$.

36. ClinicalTrials.gov. Initial and chronic methicillin resistant Staphylococcus aureus (MRSA) infection in cystic fibrosis (CF) (TRI-STAR): ClinicalTrials.gov Identifier: NCT02684422 [cited 2016 October 2]. https://clinicaltrials.gov/ct2/show/NCT02684422.

37. ClinicalTrials.gov. Ceftaroline diffusion into cerebrospinal fluid of children. ClinicalTrials.gov identifier: NCT02600793 [cited 2016 October 2]. https://clinicaltrials.gov/ct2/show/NCT02600793.

38. Cannavino CR, Nemeth A, Korczowski B, et al. A Randomized, prospective study of pediatric patients with community-acquired pneumonia treated with ceftaroline versus ceftriaxone. Pediatr Infect Dis J. 2016;35(7):752-9.

39. Korczowski B, Antadze T, Giorgobiani M, et al. A multicenter, randomized, observer-blinded, active-controlled study to evaluate the safety and efficacy of ceftaroline versus comparator in pediatric patients with acute bacterial skin and skin structure infection. Pediatr Infect Dis J. 2016;35(8):e239-47.

40. Taboada M, Melnick D, Iaconis JP, et al. Ceftaroline fosamil versus ceftriaxone for the treatment of community-acquired pneumonia: individual patient data meta-analysis of randomized controlled trials. J Antimicrob Chemother. 2016;71(4):862-70.

41. Blumer JL, Ghonghadze T, Cannavino C, et al. A multicenter, randomized, observer-blinded, active-controlled study evaluating the safety and effectiveness of ceftaroline compared with ceftriaxone plus vancomycin in pediatric patients with complicated community-acquired bacterial pneumonia. Pediatr Infect Dis J. 2016;35(7):760-6.

42. Shirley DAT, Froh DK. Agranulocytosis in a pediatric patient treated with ceftaroline. J Pediatric Infect Dis Soc. 2016;5(2):e5-8.

43. Yam FK, Kwan BK. A case of profound neutropenia and agranulocytosis associated with off-label use of ceftaroline. Am J Health Syst Pharm. 2014;71(17):1457-61.

44. Farhat NM, Hutchinson LS, Peters M. Elevated international normalized ratio values in a patient receiving warfarin and ceftaroline. Am J Health Syst Pharm. 2016;73(2):56-9.

45. Furtek KJ, Kubiak DW, Barra M, Varughese CA, Ashbaugh CD, Koo S. High incidence of neutropenia in patients with prolonged ceftaroline exposure. J Antimicrob Chemother. 2016;71(7):2010-3.

46. LaVie KW, Anderson SW, O'Neal HR Jr, Rice TW, Saavedra TC, O'Neal CS. Neutropenia associated with long-term ceftaroline use. Antimicrob Agents Chemother. 2015;60(1):264-9.

47. Autry EB, Rybak JM, Leung NR, et al. Pharmacokinetic and pharmacodynamic analyses of ceftaroline in adults with cystic fibrosis. Pharmacotherapy. 2016;36(1):13-8.

48. Burnett YJ, Echevarria K, Traugott KA. Ceftaroline as salvage monotherapy for persistent MRSA bacteremia: a review of current literature. Ann Pharmacother. 2016;50(12):1051-9.

49. Ho TT, Cadena J, Childs LM, Gonzalez-Velez M, Lewis JS 2nd. Methicillin-resistant Staphylococcus aureus bacteraemia and endocarditis treated with ceftaroline salvage therapy. J Antimicrob Chemother. 2012;67(5):1267-70.

50. Lin JC, Aung G, Thomas A, Jahng M, Johns S, Fierer J. The use of ceftaroline fosamil in methicillin-resistant Staphylococcus aureus endocarditis and deep-seated MRSA infections: a retrospective case series of 10 patients. J Infect Chemother. 2013;19(1):42-9.

51. Williams AW, Newman PM, Ocheltree S, Beaty R, Hassoun A. Ceftaroline fosamil use in 2 pediatric patients with invasive methicillin-resistant Staphylococcus aureus infections. J Pediatr Pharmacol Ther. 2015;20(6):476-80.

52. Sakoulas G, Nonejuie P, Kullar R, Pogliano J, Rybak MJ, Nizet V. Examining the use of ceftaroline in the treatment of Streptococcus pneumoniae meningitis with reference to human cathelicidin LL-37. Antimicrob Agents Chemother. 2015;59(4):2428-31.

53. Hahn A, Frenck RW Jr, Allen-Staat M, Zou Y, Vinks AA. Evaluation of target attainment of vancomycin area under the curve in children with methicillin-resistant Staphylococcus aureus bacteremia. Ther Drug Monit. 2015;37(5):619-25.

54. Welsh KJ, Abbott AN, Lewis EM, et al. Clinical characteristics, outcomes, and microbiologic features associated with methicillin-resistant Staphylococcus aureus bacteremia in pediatric patients treated with vancomycin. J Clin Microbiol. 2010;48(3):894-9. 
55. Liu C, Bayer A, Cosgrove SE, et al. Clinical practice guidelines by the Infectious Diseases Society of America for the treatment of methicillin-resistant Staphylococcus aureus infections in adults and children. Clin Infect Dis. 2011;52(3):e18-55.

56. Merck \& Co. I. Cubicin [package insert]. Whitehouse Station, NJ. 2015.

57. Mushtaq S, Livermore DM. AmpC induction by ceftaroline. J Antimicrob Chemother. 2010;65(3):586-8.

58. Chow JW, Fine MJ, Shlaes DM, et al. Enterobacter bacteremia: clinical features and emergence of antibiotic resistance during therapy. Ann Intern Med. 1991;115(8):585-90.
59. Kaye KS, Cosgrove S, Harris A, Eliopoulos GM, Carmeli Y. Risk factors for emergence of resistance to broad-spectrum cephalosporins among Enterobacter spp. Antimicrob Agents Chemother. 2001;45(9):2628-30.

60. Livermore DM, Mushtaq S, Warner M, James D, Kearns A, Woodford N. Pathogens of skin and skin-structure infections in the UK and their susceptibility to antibiotics, including ceftaroline. J Antimicrob Chemother. 2015;70(10):2844-53. 